\title{
A FORMAÇÃO DE PROFESSORES E A EDUCAÇÃO DE AUTISTAS
}

\author{
Sílvia Ester Orrú \\ Fundação de Encino Octavio Bastos, Brasil
}

O autismo, segundo Gillberg (1990) é uma "síndrome comportamental com etiologias múltiplas e curso de um distúrbio de desenvolvimento". Tem como característica sintomática a tendência ao isolamento. De acordo com a ASA - Autism Society of América, (1999) ,"o autismo é um distúrbio de desenvolvimento, permanente e severamente incapacitante". Contudo, embora haja limitações e inabilidades, antes de ser autista, esse indivíduo é um ser humano.

$\mathrm{Na}$ falta de um trabalho multidisciplinar que veja a pessoa com autismo como um ser bio-sociopsico-histórico-cultural, a mesma perpassa pelo estigma das incapacidades e inabilidades como sendo os definidores de seu destino durante toda sua vida. Logo, leva-se em conta muito mais os aspectos sintomáticos da síndrome do que a procura de estratégias interventivas para a superação das dificuldades encontradas. A exclusão social do autista emerge das concepções pré-conceituadas a respeito das "coisas" que essa pessoa não consegue fazer.

As concepções são responsáveis pelo contorno da visão de mundo do ser humano. São fundamentadas em respaldo teórico, científico e empírico. Sendo assim, o ser humano mergulha na crença do que Ihe é transmitido por outrem, esquecendo-se, na maioria das vezes, de investigar outras áreas do conhecimento que podem contextualizar melhor a delimitação de seu problema.

Voltando para a questão autismo $x$ ser humano, pleiteamos contra o pré-conceito que, baseado nos aspectos sintomáticos da síndrome, exclui a pessoa autista do direito à vida junto com outras pessoas sem o autismo. Como exemplo, citamos a tendência ao isolamento como uma das características do autismo. Será correto afirmar que por meio da influência desta característica todos os autistas não devem, não podem ou não conseguem viver próximos a outras pessoas?

Uma das responsabilidades do educador é a de intervir na vida humana por meio da reflexão e da ação reflexiva, geradoras de estratégias pedagógicas para o bem comum do educando. Logo, se é impossível fazer de conta que o autismo não existe, certamente podemos, enquanto educadores, nos dispormos à busca de maneiras inovadoras, facilitadoras, diferenciadas e produtivas para a construção de uma melhor qualidade de vida para a pessoa com autismo.

Para tanto, somente será possível tal ação, se nos despojarmos dos pré-conceitos estabelecidos como definidores de destinos. É imprescindível que o educador e qualquer outro profissional que trabalhe junto a pessoa com autismo seja um conhecedor da síndrome e de suas características inerentes. Porém, tais conhecimentos devem servir como sustento positivo para o planejamento das ações a serem praticadas e executadas e não como desculpas para o abandono à causa. Tomando as palavras de Rivière (1984): 
Esta tarefa educativa é provavelmente a experiência mais comovedora e radical que pode ter o professor. Esta relação põe à prova, mais do que nenhuma outra, os recursos e as habilidades do educador. Como ajudar aos autistas a aproximarem-se de um mundo de significados e de relações humanas significativas? Que meios podemos empregar para ajudá-los a comunicarem-se, atrair sua atenção e interesse pelo mundo das pessoas para retirá-los do seu mundo ritualizado, inflexível e fechado em si mesmo?

Quando percebermos que dentre muitas coisas que precisam passar a ter significado para o autista, muitas outras também precisam ser apropriadas e compreendidas por nós, é que transformamos a condição de excluído em seu mundo para incluído em nosso mundo. Deste modo, teremos modificado as nossas próprias vidas, pois nos abrimos para uma nova concepção de mundo.

A teoria da Modificabilidade Cognitiva Estrutural, uma verdadeira filosofia de vida, fora desenvolvida por Reuven Feuerstein, nascido na Romênia no ano de 1921, estando inteiramente relacionada ao contexto social e cultural em que vivia desde pequeno.

Consoante a entrevista realizada por Longhi (1994, p. 1-10), Reuven Feuerstein, o quinto filho de uma família de nove filhos, fora criado numa comunidade judaica, aprendendo desde os três anos de idade os textos sagrados da Bíblia Hebraica com seu pai que era rabino. Cedo, desenvolveu o desejo de comunicar seu conhecimento aos outros. Nos anos trinta, a Comunidade Judaica representou cinqüenta por cento da cidade natal de Reuven.

Nos meados da década de cinqüenta, Feuerstein deu origem a sua teoria da Experiência de Aprendizagem Mediatizada ${ }^{1}$ (EAM), que dá suporte ao mediatizador, interpondo-se e intervindo entre aquele que é mediatizado e os estímulos apresentados, adaptando-os às suas próprias necessidades.

A teoria da Experiência de Aprendizagem Mediatizada (EAM), explica a função das experiências relacionadas com o desenvolvimento cognitivo das novas gerações como um acontecimento ou um processo de criação e modificação de um ser através da transmissão ou melhor, da construção da cultura de um povo, seus valores, atitudes, intenções, etc., já experimentados e realizados pelas gerações anteriores, com a finalidade de se obter certo resultado desejado. Deste modo, percebe-se que o desenvolvimento cognitivo humano de quem é mediatizado, existe sempre junto com o desenvolvimento cognitivo de seus mediatizadores, sucedendo-se, naturalmente, dentro de um contexto social que pode tanto contribuir para o crescimento de seu desempenho como provocar disfunções cognitivas ou um desenvolvimento deficitário das mesmas.

Portanto, notase claramente que Feuerstein não desenvolveu apenas uma nova teoria de ensinoaprendizagem, mas sim, uma filosofia otimista que contradiz a delimitação e o fatalismo incitados pela genética, crendo e consolidando sua posição de que todo o ser humano é modificável e para que tal modificação aconteça, é preciso haver a mediatização como sendo uma estratégia de intervenção por meio

\footnotetext{
${ }^{1}$ Preferimos o uso do termo mediatizada do que mediada por, este primeiro, inferir como algo acima do ato de mediar, pois transcende do sujeito para fora dele, além de um nível de limite imposto, supondo uma intervenção de um princípio que lhe excede.
} 
de um mediatizador que primará por sua qualidade, visando produzir efeitos no organismo do mediatizado, buscando melhor eficácia no processamento de sua informação. Seu método tem sido aplicado em países variados, nas mais diversas culturas, com o firme propósito de favorecer o progresso educacional nas sociedades multiculturais, envolvendo educadores e alunos no processo de modificabilidade cognitiva estrutural.

Para Feuerstein, a interação e o envolvimento com o material e o professor, não são suficientes para que haja a experiência de aprendizagem mediatizada. É preciso haver um mediatizador responsável, afetivo, conhecedor e competente para ser o intermediário entre o mediatizado e a experiência de aprendizagem mediatizada. Assim, é notório que Feuerstein tem maior preocupação de como se dão os processos mentais do indivíduo e com a formulação de programas que o enriqueçam cognitivamente do que com os resultados obtidos por testes que medem a capacidade intelectual, idéia que enfatiza sua influência advinda das obras de Vygotsky, além das de Piaget e de Bruner. Tal como Vygotsky, Feuerstein não menospreza as definições biológicas da espécie humana, mas valoriza a proporção em que se dá o contexto histórico e social do ser humano, de onde são fornecidos os instrumentos e os símbolos que estão entre o indivíduo e o mundo que o rodeia, proporcionando mecanismos psicológicos que lhe darão auxílio em sua ação sobre sua realidade, processando-se através desse aprendizado o desenvolvimento das funções psicológicas superiores.

A utilização da Experiência de Aprendizagem Mediatizada como uma das formas de inteirar-se o indivíduo com seu meio, consiste na transformação de todos os estímulos através de um mediatizador que os criterize, organizando-os e modificando-os para uma melhor interpretação do universo que o rodeia e no qual ele está inserido, proporcionando condições para uma melhor qualidade em seu desenvolvimento intelectual.

Para Feuerstein, a mediação conceitua-se como um processo pelo qual se desenvolve uma interação entre um indivíduo com funções cognitivas deficientes ou insuficientes com um outro indivíduo que já possua um conhecimento experiente com visão intencionada para provocar modificações ou aperfeiçoamento de tais funções cognitivas. De modo que essa mediação seja compreendida como o resultado combinado da exposição direta do indivíduo com o meio e à experiência de aprendizagem mediatizada, que tem seu planejamento e avaliação desenvolvidos pelo mediatizador, que deve estar sempre atento às necessidades do indivíduo que será mediatizado, levando-se em conta sua cultura que é a base para a existência de significados para os estímulos propostos. $O$ ato de mediatizar deve estar intencionalmente ligado ao propósito de se enriquecer os fatores relacionados ao cognitivo, para que estes se voltem para os significados existentes no mundo em que se vive, a fim de se desenvolverem no indivíduo condições necessárias para se adaptar e modificar-se, conflitando-se com as determinações culturais pelas quais atravessa em seu cotidiano. Sem dúvida, a mediatização pode ser vista como uma estratégia, um esquema de intervenção por meio de uma interferência humana do mundo exterior para o organismo do indivíduo mediatizado e, dependendo da qualidade desta intervenção, da sua pedagogia, da sua sensibilidade, da sua observação e atenção aos detalhes evidenciados por meio de coleta de dados sobre o indivíduo, será maior a eficácia de processamento de informação do indivíduo, quando este, for novamente exposto a outros diferentes estímulos, provocando a modificabilidade de estruturas cognitivas. 
A exposição do indivíduo à mediatização é que provoca mudanças das estruturas que processam e alteram os estímulos diretos; por isso há prioridade em se ter um mediatizador que atue consciente e intencionalmente sobre as estruturas cognitivas e não uma pessoa que atue esporadicamente ou arbitrariamente quando lhe convenha. Não são os ambientes enriquecidos de estímulos que estruturarão os alunos cognitivamente, mas sim, os educadores mediatizadores que exploram de forma sistemática e planificada os estímulos, relacionando-os ao aluno mediatizado, livrando-o da privação cultural e do fracasso escolar. Logo, a teoria desenvolvida por Peuven Feuerstein é um belive system e não permite considerações negativistas sobre o potencial de aprendizagem de qualquer pessoa, seja qual for sua condição. Portanto, o que se dirá a respeito da inteligência das crianças com autismo?

A formação de educ adores mediatizadores é um processo de modificação cognitiva estrutural que precisa ocorrer no interior desse candidato à profissão de educador, através da Experiência de Aprendizagem Mediatizada que deve ser vivenciada e experimentada em sua sala de aula, em meio ao seus estudos como uma filosofia inerente ao curso que está sendo realizado. Desta forma, a qualidade do ensino seria melhorada, pois a modificação seria estrutural e não apenas postural, quando o professor assume seu trabalho dentro de uma proposta pedagógica, por ser este ou aquele, o método enfatizado na época.

$\mathrm{Na}$ Experiência de Aprendizagem Mediatizada, não se concebe a possibilidade de haver indivíduos estáticos ou imutáveis. Portanto, esta intervenção a ser realizada pelo educador se conduzirá de modo intencional nos sistemas disfuncionais de alunos com necessidades específicas, interagindo em sua realidade, em um processo de modificação, para que suas condições de funcionamento cognitivo sejam estruturadas, potencializando-os em suas capacidades adaptativas. A não conformidade proposta por esta teoria desenvolvida por Reuven Feuerstein, dá subsídios para que pessoas com necessidades especiais também sejam trabalhados de forma educativa, estando sujeitos a serem modificados através do mediatizador que procurará transformar sua situação de isolamento e maneirismo em interação e equilíbrio, num processo contínuo de enriquecimento mútuo e fortalecimento do $e u$, potencializando suas habilidades específicas através da mediatização intencional e recíproca.

Pensando na pessoa com transtornos invasivos do desenvolvimento e sua complexidade, clarificanos de modo crucial que a aprendizagem por meio de exposições diretas a estímulos diversos, tanto visuais como auditivos ou táteis não contribui para sua formação intersocial e desempenho das estruturas cognitivas. Tal indivíduo exposto a estímulos visuais diversos sem a devida intervenção do educador, tornarse-á estressado por causa da saturação de informações que a ele permanecem infuncionais. Ele registrará os estímulos e até poderá interagir com os mesmos; contudo, mesmo que ocorram modificações em seu processo cognitivo, esta aprendizagem não será suficiente para dar origem a níveis de qualidade e modelos básicos de desenvolvimento cognitivo por apenas exercitar habitualmente as relações sujeito-objeto. Entretanto, com a Experiência de Aprendizagem Mediatizada, este aluno poderá alcançar níveis de desenvolvimento, hierarquização e complexidade cognitiva por meio da atuação do educador-mediatizador que intervirá entre os estímulos e o próprio aluno, a partir da intencionalidade da mediatização que 
adequará tais estímulos às suas vicissitudes específicas, sendo esta, a responsável pelas principais transformações nas estruturas cognitivas do ser humano.

Para o educador-mediatizador, os estímulos não têm existência vã ou ocasional. Eles existem para serem filtrados, construídos modularmente, mediatizados, intervirem a favor do aluno, fixarem aprendizagens ou mesmo para serem suprimidos conforme as necessidades colocadas e reguladas pelo mediatizador, sofrendo constante relação com o tempo, o espaço e a qualidade dos demais estímulos anteriormente trabalhados ou que virão a seguir, estando impregnados e engastados de toda significação.

Se a mediatização é algo que caracteriza a espécie humana, logo, antes de qualquer coisa, toda pessoa é um ser humano propenso à modificações. Ela acontece em toda a história da humanidade, tornando inteligível e justificável o papel das experiências interativas que no desenvolvimento cognitivo das gerações mais novas, sucede por meio de transmissão cultural, envolvendo valores, atitudes, intecionalidades e outras ações que foram e são realizadas pelas gerações mais velhas, tendo em vista, a produção de certos efeitos que são desejados. É desta forma que a espécie humana continua desenvolvendo aquisições extra-biológica e extra-ecológica, caracterizando-se como própria e sapienticidade através da mediatização intrínseca dos mediatizadores e condutores de cultura. Assim, todo indivíduo modifica-se cognitivamente se for submetido a Experiência de Aprendizagem Mediatizada, podendo-se, inclusive, atribuir a ela a própria origem social da linguagem e do pensamento humano em razão da mediatização cognitiva, simbólica e cultural já estudadas por Vygotsky, além de ser um fator relevante na explicação da própria evolução humana como sendo o desenvolvimento humano o produto da interação entre o indivíduo e os estímulos e o mediatizador, de modo a atuar e introduzir produtos necessariamente eficazes no organismo do indivíduo que se submete à aprendizagem.

Os desafios e as complexidades situacionais devem ser provocadas pelo mediatizador conforme seja a competência dos mediatizados, procurando encorajá-los à curiosidade intelectual, promovendo originalidade e criatividade, propondo atividades não-convencionais, estimulando-os ao envolvimento e à superação dos obstáculos propostos, apresentando modelos para terem êxito em sua aprendizagem, incentivando-os e conscientizando-os de seu potencial e capacidade de superação de situações inovadoras e complexas, etc. Tais atividades devem ocorrer dentro do plano da EAM, a fim de promover a modificabilidade cognitiva estrutural nos alunos, devida a interação provocada sob os critérios estabelecidos e norteadores de um processo construtivo, dialético, capacitador e positivo para o desenvolvimento pleno do indivíduo.

De acordo com Reuven Feuerstein (apud FONSECA, 1998, p. 70-76), são dez os critérios ou formas de interação fundamentais para a mediatização. Os três primeiros critérios são necessários e satisfatórios para que uma interação seja reconhecida como mediatização e os sete outros critérios podem funcionar em momentos distintos, segundo a precisão e sua relevância como pontos de equilíbrio e de auxílio uns aos outros, dispondo de um processo aberto e dinâmico com flexibilidade de aplicação e sujeito a modificações. Os critérios bases da EAM são: Intencionalidade e Reciprocidade; Compartilhamento; Significado; Individuação; Transcendência; Planejamento de objetivos; Competência; Desafio; Autoregulação e controle do comportamento e Auto-modificação. 
Assim, o educador-mediatizador abrilhanta a interação da criança com seu meio ambiente a partir de elementos não pertencentes à circunstâncias imediatas, mas com a partir de um universo significativo e intencional processado pela deriva de gerações anteriores transmissoras de significados, atitudes, princípios, valores e alvos culturalmente assistidos, transmitidos e construídos. Os dez critérios para a realização da mediatização são como peças de um quebra-cabeças que se unem e complementam-se entre si, formando uma visão única e objetiva.

Portanto, a EAM gera a modificabilidade cognitiva estrutural nas pessoas por meio da interação encontrada em seus critérios. Ela é incondicional, possível a quaisquer pessoas, independente de possuírem ou não necessidades educacionais específicas. A EAM espera ${ }^{2}$ que todas as pessoas, submetidas a mediatização, atinjam um nível mais avançado daquele que possuíam anteriormente, estando abertas para novos caminhos de desenvolvimento intelectual. Conforme Vítor da Fonseca:

A EAM, desde que se observem os critérios anteriormente apresentados, é muito mais que uma filosofia educacional, é um sistema de crença que crê na autoplasticidade humana, na necessidade que qualquer ser humano possui de atingir a competência e a maestria e de aumentar os seus níveis de auto-realização. (Op. cit., 1998, p. 77).

Com a finalidade de colocarmos em prática a EAM para a educação de pessoas com autismo, primeiramente, trabalhamos com as cinco educadoras por um período de dez meses ${ }^{3}$. Durante esse período, proporcionamos orientações teórico-práticas dentro e fora da sala de aula, conhecimentos científicos sobre a síndrome do autismo e demais patologias associadas e diagnosticadas em seus alunos, o perfil básico sobre seu aluno e seu contexto histórico, encontros para discutir a prática pedagógica, leituras e discussões sobre a teoria adotada para a educação de pessoas com autismo e o porquê de sua escolha. Também praticamos avaliações dinâmicas sobre o desenvolvimento do aluno com autismo a partir da nova proposta pedagógica trabalhada.

Cremos que, para promover a educação à pessoa com autismo, é preciso, antes de mais nada, promover transformação na vida pessoal e profissional do educador como forma de inovar o processo educativo junto ao aluno com autismo.

Para tanto, partimos de três categorias com o fim de enriquecer o processo pelo qual se dá o conhecimento científico da prática docente. São elas: a reflexão na ação do educador, a conscientização do que seja a profissão docentee a inovação como resultado das práticas investigativas.

A escolha pela teoria da Modificabilidade Cognitiva Estrutural decorreu da postura filosófica de vida que ela exige, sendo um referencial que provoca a reflexão no educador. O educador, por sua vez, reflete sobre suas ações já praticadas e, baseando-se nessas experiências já vivenciadas, reflete sobre as ações que virá a praticar. Outro motivo de sua escolha foi devido a sua abertura e liberdade para que o educador

\footnotetext{
${ }^{2}$ Espera não no sentido de possuir dúvidas a respeito, mas espera com certeza na concretização do fato a ser manifestado no momento certo, com naturalidade.

${ }^{3}$ Ano letivo de 2000 .
} 
seja ele mesmo, sem a imposição de regras preestabelecidas com ausência de adequação à realidade vigente e sem "receitas" prontas sobre como trabalhar com o aluno.

O suporte didático firmado nos dez critérios da Experiência de Aprendizagem Mediatizada consolida o objetivo proposto de valorizar a prática docente, pois tais critérios proporcionam êxito nas ações com os alunos através da incitação do educador a refletir sobre seus atos, sem, ao mesmo tempo, ferir as características individuais de cada aluno.

Para que a prática docente tome consistência, observamos a necessidade das educadoras comunicarem-se e partilhar suas idéias, incertezas e experiências com demais colegas. Registra-se, deste modo, o valor e a relevância das discussões em grupo, para a prática reflexiva na vida do educador.

A medida em que as educadoras foram conhecendo seus alunos, o conhecimento teórico foi adentrando à sala de aula. Visamos criar com as educadoras, um semelhante vínculo procurado por elas com relação a seus alunos. Assim como suas ações deveriam ser reflexivas e mediatizadas no atuar com o aluno, o nosso relacionamento pessoal e profissional com as educadoras era de reflexão e mediatização daquilo que thes era novo ou pouco conhecido com seus conhecimentos e experiências já adquiridas durante o período de formação e tempo de docência.

Parece salientar que, tal como foi dito por Dewey: "o mero conhecimento dos métodos não basta, pois é preciso que exista o desejo e a vontade de os empregar" (1989, p. 43 apud GARCIA, 1995, p. 62). Para que esta vontade de empregar os métodos ocorra, gradativamente, na educação de pessoas com autismo, é preciso refletir sobre o paradigma normalidade/anormalidade. Esta reflexão visa explorar as questões voltadas para o preconceito que parcializa as ações de muitos profissionais, limitando a concepção de novas idéias, novas formas de trabalho, diferentes buscas para a resolução de problemas. $O$ educador desmotivado e inseguro sobre sua função a exercer, em geral, tende a cumprir seu horário de trabalho e dirigir-se a seu lar sem ânimo para inovar. É de suma importância que a reflexão-na-ação alcance, não apenas os professores em sua prática docente, mas, inclusive, seja hábito dos coordenadores e diretores dos estabelecimentos de ensino. A valorização por parte dos dirigentes, relacionada à responsabilidade intelectual do educador, deve andar junto com a valorização de sua prática diária. Ambas, refletirão no entusiasmo do educador contra a rotina que o persegue.

Observamos que, embora as educadoras entrevistadas já possuíssem uma formação destinada ao ensino e tempo de prática docente, a convivência com o novo as fascinava. $O$ ato de conhecer seu aluno, de participar de sua vida e de atribuir atenção às suas necessidades específicas, contribuiu, imensamente, para mediatizar o processo de ensino e aprendizagem. Notamos que as características inerentes à síndrome do autismo passam a ser melhor detectadas, conhecidas e compreendidas pelas educadoras. Isto prova que, apesar do conhecimento científico adquirido por meio de leituras, estudos e orientações, a prática docente junto a esse aluno com autismo, intensificou o grau de conhecimento já possuído.

Entretanto, não são apenas esses dois fatos que dão origem ao sucesso no trabalho do educador. É preciso que teoria e prática caminhem lado a lado, circunferenciadas pela ação reflexiva. Esta tripla união insere 
outros significados na vida do educador, pois sua forma de olhar o aluno é transformada e dirigida por princípios e valores que trarão profundidade em suas ações.

Como a vida é, terminantemente, cheia de surpresas e de possibilidades, mesmo que o educador se mantenha dedicado no aprender através de conhecimentos científicos e por meio de sua prática reflexiva, momentos de incertezas podem surgir. Porém, são essas situações que, as vezes, se apresentam meio emaranhadas, que constróem degraus para a superação de si próprio. Tais momentos devem ser encarados como desafios encorajadores, determinantes de uma nova busca a respostas não imediatistas, mas construtivas para a contínua mutabilidade do ser humano.

Para nós fica claro que, encorajar os educadores a se tornarem profissionais reflexivos, proporcionando liberdade para exprimirem seus æntimentos, suas idéias, expandirem sua criatividade, tomarem decisões a partir de seu conhecimento e vivência diária com o aluno é fundamental para um processo de formação reflexiva contínua e de transformação consistente. O espaço para gerar reflexão é indispensável.

Assim, o educador aprende a refletir-na-ação a partir do instante em que começa a fazê-lo. Essa atitude permitir-Ihe-á perceber, organizar, transformar e reestruturar suas ações quer sejam a nível intencional, estratégico ou hipotético. Então, sim, obter-se-á uma educação diferente, não por imposição ou por modismo, mas apoiada na prática reflexiva de seus professores.

No relato de todas as educadoras percebemos que, no início do trabalho junto aos alunos com autismo, todas passaram por momentos de intensa insegurança, medo, sentimento de incapacidade e desânimo. Quando iniciamos a nova proposta com as educadoras, solicitamos que anotassem todas e quaisquer atitudes de seus alunos que thes fossem marcantes ou thes parecessem importantes em um caderno destinado para este fim. Notamos que nos fixaram os olhos como quem perguntava: "anotar o que?". De propósito, não demos muitos exemplos sobre o que anotar. Tínhamos a intenção de provocarIhes um desafio que as incitassem a observar e conhecer seus alunos. $O$ fato de serem alunos com autismo parecia deixá-las sob certo impacto, pois, afinal de contas, pareciam não reagir ou não se importarem com o que quer que fosse que elas fizessem. Porém, num silêncio inquiridor, as educadoras tomaram posse dos cadernos. Explicamos que os mesmos serviriam para o nosso acompanhamento sobre o desenvolvimento dos alunos. Porém, nossa intenção ia além disso. Pensávamos na possibilidade de uso das anotações realizadas para momentos não planejados em que o conhecimento na ação pudesse nascer a partir de reflexões solitárias e, finalmente, em reflexões coletivas.

Esta experiência nos mostra que "o profissional reflexivo constrói de forma idiossincrática o seu próprio conhecimento profissional, o qual incorpora e transcende o conhecimento emergente da racionalidade técnica" (GÓMEZ, 1995, p. 110). Deste modo, entendemos que a utilidade do conhecimento teórico adquirido durante a formação docente ocorre de maneira significativa a partir do enfrentar de situações cotidianas que, lentamente, alicerçam o pensamento prático do educador através da reflexão na ação e também pela reflexão sobre a ação exercida. 
Observamos que, como conseqüência dos momentos de reflexão-na-ação dentro da prática docente das educadoras, estabeleceu-se a integração da ação investigadora no dia a dia com o aluno. Notamos que o ato de investigar motivou-as para um maior interesse sobre quem é o seu aluno e como se dá a sua aprendizagem.

É importante salientar que o êxito alcançado com essa nova proposta de trabalho com alunos autistas é conseqüência do trabalho realizado pelo professor. Contudo, além de um segmento teóricoprático norteador das ações das educadoras, existe a vontade e a perseverança de cada uma. Para nós, fica claro que a reflexão na prática docente e sobre ela é um ato desencadeador de uma profissionalidade consciente. Ela permite e provoca o agir e o refletir sobre si mesmo, dialoga com o educador enquanto pessoa e profissional. $O$ ato de fazer reflexão é determinante sobre as ações do profissional docente. Este, por sua vez, vai sendo envolvido de tal forma, pelo processo de construção do conhecimento a partir de seu diálogo com a teoria e sua prática, que passa a esculpir-se sob um perfil de compromisso com seu aluno e, consequentemente, com uma educação de qualidade.

A chance de recolher o aluno com autismo do isolamento que o caracteriza depende da qualidade da relação do educador com o mesmo. Por isso, é importante que o educador contenha uma revelação e expressão interessantes, de modo a cativar esse aluno.

Esta não é uma tarefa fácil para o educador, no entanto, também não é impossível de ser realizada. O universo da educação de um aluno com autismo é, deveras, complexo para o abordarmos de forma singela. Toda a pessoa que se forma para assumir a responsabilidade de ser um educador precisa ser compromissado com a causa que faz dele um profissional. Porém, o educador que recebe um aluno com autismo em sua sala de aula necessita exercitar e preservar algumas características em sua personalidade como parte indissolúvel de seu compromisso com a educação.

Cremos que uma das características indispensáveis do educador compromissado com a educação é manter-se com uma postura que o abranja como um todo, isto é, ter uma filosofia de vida que implique sua maneira de ser e de ver o mundo. Deste modo, refletimos sobre nossas ações e em nossas ações, tendo sempre em vista o ensino e a educação da pessoa com autismo, levando-se em conta seu potencial e habilidades específicas como pontos de partida.

Idealizar como deve ser a educação no país é diferente de preparar profissionais para efetuarem seu trabalho dentro de uma realidade fria e diferente do que foi idealizado. A formação do docente não pode acontecer desvinculada do contexto sócio-cultural que o contorna, não pode ocorrer de forma fragmentada à realidade vigente. Caso se dê desta maneira, o docente encontrar-se-á desajustado e inapto para assumir seu posto de educador, pois sua formação não corresponderá às exigências do real cotidiano.

Pessoas com autismo manifestam dificuldades para manter relações. Aqui, o termo "relações" abrange desde um determinado indivíduo, objeto e, até mesmo, determinados momentos ou situações em que se encontram inseridas. Para tanto, é importante que o aluno tenha previsibilidade dos acontecimentos diários. Isto não quer dizer que, por um dado motivo, o educador não possa fazer alterações em seu planejamento. Contudo, em geral, o ser humano sente-se bem quando é respeitado e aprecia o momento 
em que é avisado sobre a impossibilidade de realização de um compromisso, anteriormente, marcado. Semelhante coisa acontece com a pessoa autista.

Existem vários programas, métodos e recursos de comunicação alternativa que auxiliam no trabalho com pessoas que possuem déficits nas habilidades de comunicação. Nós fizemos uso do The Picture Communication Symbols. Dos dez casos de alunos com autismo, apenas três verbalizam. Atualmente, todos apresentam dificuldades para elaborar e representar graficamente o que desejam expressar, o que nos limita a realização de um trabalho mais individualizado onde, eles mesmos, poderiam criar e estabelecer os seus próprios símbolos. Portanto, o emprego do PCS tem sido de grande utilidade com nossos alunos.

O uso do PCS não ocorre de forma padronizada com todos os alunos. Foram necessárias adequações para cada aluno. Seis deles possuem sua própria agenda individual afixada na sala de aula. Um dos alunos utiliza um mini-álbum de fotografias como sua agenda diária. Dois alunos são trabalhados com o uso do PCS, porém, não possuem agendas.

O educador que faz uso das agendas individuais, organiza o dia de seu aluno na ordem dos acontecimentos utilizando símbolos visuais como "pistas" para a previsibilidade e compreensão significativa do que ocorrerá. Para o aluno não verbal, esse recurso é como uma ferramenta, uma prótese, pois, devido a sua maior habilidade de compreensão se dar de forma visual, os objetos e situações dispostos a partir de símbolos visuais adquirem um significado mais expressivo.

Entretanto, assumindo o papel de mediatizador no processo de ensino e aprendizagem e, tendo a teoria da Modificabilidade Cognitiva Estrutural como referencial teórico, o educador procura não fazer dos símbolos utilizados um elemento de dependência. Ressaltamos que o nível de melhora dos alunos foi significante a partir do instante em que passamos a fazer uso do PCS, no entanto, visualizamos sua utilidade como um apoio pedagógico para a educação dos mesmos e não seu treino.

No momento em que o educador percebe que houve a internalização significativa do estímulo apresentado com o símbolo visual e com a palavra sonoramente emitida, ele passa a explorar as mesmas situações ou objetos (estímulos) diminuindo a apresentação visual dos símbolos. Esta atuação tem se revelado relevante no processo de modificabilidade para a independência e autonomia do aluno, além de estimular sua verbalização.

Contudo, alguns dos alunos se encontram ancorados na utilização do PCS. Segundo suas educadoras, houve presença de melhoras no desenvolvimento da aprendizagem e compreensão a partir do uso de símbolos.

Um fator de suma importância é a observação constante do educador para o aluno e seu modo de interagir com os símbolos visuais. Nem todas as pessoas com autismo manifestam boa tolerância para com esse recurso ou para com as formas citadas de sua utilização. Logo, seu uso não precisa ser regra padrão, mas deve ser contextualizado individualmente, objetivando benefícios para essa pessoa. 
O aluno R.F. com síndrome de Asperger possui um mini-álbum de fotografias como sua agenda pessoal. Esta, serve para a sua organização e previsibilidade dos acontecimentos. Permite e incita também, sua organização intrínseca, diminuindo seu estado de ansiedade.

Temos observado que o uso de símbolos visuais auxilia para o melhor nível de comunicação receptiva e emitiva do aluno, na compreensão significativa de estímulos diversos, na redução do estado de ansiedade manifestado através de ações estereotipadas e ecolalia, na relação e interação educador-aluno, na realização de atividades, na estimulação verbal, na diminuição de hiperatividade e no nível de concentração para a realização de tarefas.

Todavia, apesar do uso do PCS, todas as educadoras mantêm um diálogo constante com seus alunos. Não menosprezam o uso de gestos, de expressão facial e corporal, de entonação de voz de acordo com a situação, de tentativas e manutenção de toques táteis, etc.

Ao vivermos esta experiência com as cinco educadoras e seus alunos, experimentamos um sabor diferente no processo de ensino e aprendizagem. Também desfrutamos de um seguimento desafiador e exigente de nós mesmos para o preparo das educadoras no atuar com seus alunos. Podemos afirmar que a reflexão na ação e sobre nossa ação esteve presente a cada página deste trabalho, pois tínhamos que nos entregar a ela para encontrarmos caminhos alternativos e respostas para nossas interrogações pessoais e profissionais. Tal responsabilidade nos gerou, simultaneamente, o olhar sobre nós mesmos enquanto profissionais docentes em construção a partir da articulação do conhecimento científico adquirido com a nossa experiência vivida e praticada. A esses momentos de sucessivas aprendizagens e ao novo sabor experimentado nesse processo, damos o nome de inovação como resultado das práticas investigativas. Com certeza, outras categorias poderiam ser levantadas, porém, estas manteram-se presentes em nosso caminhar.

Tal como nos encontramos hoje, fica-nos claro que a formação do educador não se dá de um dia para o outro. Ela é um processo contínuo e não acabado que perpetua mesmo após a sua passagem pela academia. Portanto, os conhecimentos que são construídos e internalizados durante a formação acadêmica, as práticas reflexivas, o diálogo aberto com os colegas da mesma profissão ou de outras áreas profissionais, a troca de experiências vivenciadas, o abrir-se à criatividade, as leituras e estudos complementares, a transformação consciente de si próprio e de suas ações, a sede pelo saber, a humildade para aprender com todos, o respeito pelo ser humano e o compromisso com a escolha, função e ação da profissão docente é que constituem o educador num processo generoso da vida humana, capaz de modificar-se, provocar modificações no outro, modificar o próprio ambiente e, assim, modificar as estruturas de um país.

Neste caminho percorrido junto às educadoras e aos alunos, acentuou-nos a realidade de que o conhecimento científico é produto de um processo de construção coletiva. Pois, como pesquisadora, inserimo-nos no contexto histórico e social dos sujeitos e juntos descobrimos caminhos, alternativas de trabalho que implicaram em transformações profundas, tanto na vida dos alunos com autismo como em nossas próprias vidas. 
Para a Universidade fica este mesmo desafio: gerar inquietações que desencadeiem a busca de respostas para a superação de si mesma, enquanto formadora do futuro profissional docente que, a partir dos conhecimentos adquiridos e vinculados com a experiência pessoal e coletiva, transforme-se para proporcionar transformações ao outro. Tais desafios podem ser apresentados pela imersão na pesquisa e na ação.

Ainda não encontramos a linha finita deste horizonte. Este é um dos braços de um grande rio que desemboca no oceano. O conhecimento não tem limites. Muitas interrogações sobre as possibilidades e o modo de educar-se uma pessoa com autismo continuam aflorando. Colocar um ponto final neste trabalho é impossível e contraditório a nossos princípios norteadores.

Esperamos que este trabalho colabore para suscitar críticas e questionamentos a outros profissionais, com o propósito de dar continuidade a investigação a respeito do aluno com autismo e sobre a prática docente voltada para o objetivo de educá-lo e inseri-lo nas atividades sociais. Também desejamos que nossa experiência evidencie a relevância da ação reflexiva para o profissional docente no seu cotidiano. E tal como Reuven Feuerstein, insistimos que "a mudança é a característica mais estável dos seres humanos" (MENTIS, 1997, p. 80).

Quanto aos nossos alunos, podemos dizer que continuam nos desafiando dia após dia. Não cabe a este trabalho narrar e/ou discutir os resultados já constatados nesse processo de ensino e aprendizagem pelo qual estamos passando. Apenas podemos aguçar curiosidades sobre os desafios e surpresas que cada um deles nos têm proporcionado. Cabe a nós, educadores, a entrega de nós mesmos à paixão de conhecer melhor nossos alunos. Esta paixão que supera as barreiras e abrilhanta os olhos é redimensionada para o sorriso que atrai os alunos ao profissional docente.

\section{REFERÊNCIAS}

AMERICAN PSYCMATRIC ASSOCIATION. Diagnostic and Statistical Manual of Mental Disorders. 4aㅡ edição, Washington, DC, American Psychiatric Association, 1995 (International Version).

ASA - Autism Society of América. Autism. Departament of Health ando Human Services. Public Health Service National Institutes of Health. U.S.: 1999.

ASSOCIAÇÃO PSIQUIÁTRICA AMERICANA. Manual de Diagnóstico e Estatística de Distúrbios Mentais (DSM-III-R). São Paulo: Ed. Manole, 1989.

BAILEY, A. ; Le Couter, A. ; GOTTESMAN, L. et al. Autism as a strongly genetic disorder: evidence from a British twin study. Psychol Med 25:63-77, 1995 apud Steiner, Carlos Eduardo. Aspectos genéticos e neurológicos do autismo; proposta de abordagem interdisciplinar na avaliação diagnóstica do autismo e distúrbios correlatos. Campinas, 1998. Dissertação (Mestrado em Ciências Biológicas) Universidade Estadual de Campinas.

CADERNOS CEDES. A nova $L D B$ e as Necessidades Educativas Especiais. Campinas: v. 46, Centro de Estudos Educação e Sociedade, 1998.

CLASSIFICAÇÃO de Transtornos Mentais e de Comportamento da CID-10; Descrições clínicas e diretrizes diagnósticas. Porto Alegre: Artes Médicas, 1993.

CLASSIFICAÇÃO Estatística Internacional de Doenças e Problemas relacionados com a Saúde da CID-10. São Paulo: Edusp, 1995. 
COLL C., PALACIOS J. e MARCHESI A. Desenvolvimento Psicológico e Educação: necessidades educativas especiais e aprendizagem escolar. Tradução de Marcos A. G. Domingues. Porto Alegre: Artes Médicas, 1995.

DEWEY, J. Cómo pensamos. Barcelona: Paidós, 1989.

FEUERSTEIN, Reuven. Instrumental Enrichment. University Park Press. Baltimore, 1980.

The Dynamic Assessment of Retarded Performers: The Learning Potential Assessment Device, Theory, Instruments, and Thechiques. Baltimore: University Park Press, 1979.

FONSECA, Vítor da. A modificabilidade cognitiva na educação especial e na reabilitação. Mensagem da APAE, São Paulo: julho/setembro, 1988, p. 6-11.

. Aprender a aprender: a educabilidade cognitiva. Porto Alegre: Artmed, 1998.

Educação Especial: programa de estimulação precoce - Uma introdução as idéias de Feuerstein. $2^{\text {a }}$ ed. rev. aum. Porto Alegre: Artes Médicas, 1995.

GARCIA, Carlos Marcelo. A formação de professores: centro de atenção e pedra-de-toque. In: NÓvOA, A. (Org.). Os professores e a sua formação. 2ª edição. Lisboa: Publicações Dom Quixote, 1995.

GASPAR, Maria de Lourdes Ribeiro. Autismo: procurando vencer as barreiras impostas pelo isolamento. Mensagem da APAE. Brasília, ano XXXV, n.ำ 83, p. 13, outubro, 1998.

GILLBERG,C. Infantile autism diagnosis and treatment. Acta Psycbiat. Scand., 1990.

GÓMEZ, Angel Pérez. O pensamento prático do professor: a formação do professor como profissional reflexivo. In: NÓVOA, A. (Org.). Os professores e a sua formação. $2^{2}$ edição. Lisboa: Publicações Dom Quixote, 1995.

GRANDIN, T \& SCARLANO, M. M. Uma menina estranha. Trad. de Sérgio Flaksman. São Paulo: Companhia das Letras, 1999.

. Emergence: labeled autistic. Novato, Califórnia: Arena Press, 1986.

GRANDIN, Temple. "Needs of high functioning teenagers and adults with autism". Focus on Autistic

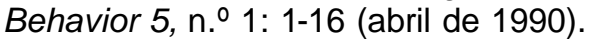

High-Functioning Individuals With Autism. Edited by Eric Shopler and Gary B. Mesibov Plenum Press, New York: 1992.

. My Experiences with Visual Thinking Sensory Problems and Communication Difficulties. Colorado: Colorado State University, February, 1996.

JOHSON, Roxanne M. Guia dos símbolos de comunicação pictórica. Trad. Giselle Mantovani e José Carlos Tonolli. Porto Alegre: Clik - Recursos Tecnológicos para Educação, Comunicação e Facilitação, 1998.

KANNER \& EISENBERG. Notes on the follow-up studies of autistic children. Psychopathology of Childhood, 1955.

KANNER, Léo. Autisc Disturbances of Affective Contact. Nervous Child, 2:217-250 (1943). Child Psychiatry, 2a ed. Springfield: Charles C. Thomas, 1948.

KOZULIN, Alex. Individualismo epistemológico frente a una posición sociocultural: Piaget, Vygotski y la teoría del aprendizaje mediado. Israel: ICELP, s.d.

LONGHI, Claudine. L'inspiration éducative de Reuven Feuerstein, fondateur du PEl. Lyon, Ce Texte a été publié dans la Lettre du Clerse, dossier n.ำ 25, février, 1994.

MAZZOTTA, J. S. Educação Especial no Brasil: história e políticas públicas. São Paulo: Cortêz, 1996.

NÓVOA, Antônio (Org.). Os professores e sua formação. Lisboa: Publicações Dom Quixote, 1995. . Profissão professor. $2^{\text {a }}$ edição. Porto - Portugal: Porto Editora Ltda, 1995.

. Vidas de professores. 2ª edição. Porto Codex - Portugal: Porto Editora Ltda, 1995.

RIVIÈRE, Angel. Modificacion de Conducta em el Autismo Infantil. Revista Espanõla de Pedagogia, v. XLII, p. 164-5, 1984. 
RUTTER, M. Languagem disorder and infantile autism. In: Rutter, M.; Schopler, E. Autism: a reappraisal of concepts and treatment. New York: Plenum Press, 1979, p. 85-103.

SACKS, Olivier. Um antropólogo em Marte. São Paulo: Companhia das Letras, 1995.

SACRISTÁN, J. G. Consciência e açção sobre a prática como libertação profissional dos professores. In: NÓVOA, Antônio (Org.). Profissão professor. $2^{\text {a }}$ edição. Porto - Portugal: Porto Editora Ltda, 1995.

SCHWARTZMAN, José Salomão. Autismo infantil. São Paulo: Memnon, 1995.

SCHÖN, Donald A. Formar professores como profissionais reflexivos. In: NÓVOA, A. (Org.). Os professores e sua formação. Lisboa: Publicações Dom Quixote, 1995.

STAINBACK, Susan. Inclusão: um guia para educadores. Tradução de Magda França Lopes. Porto Alegre: Artes Médicas Sul, 1999.

STEINER, Carlos Eduardo. Aspectos genéticos e neurológicos do autismo: proposta de abordagem interdisciplinar na avaliação diagnóstica do autismo e distúrbios correlatos. Campinas, 1998. Dissertação (Mestrado em Ciências Biológicas) - Universidade Estadual de Campinas.

VYGOTSKY, L.S. A formação social da mente. 5aㅡ ed. São Paulo: Martins Fontes, 1994. Pensamento e Linguagem. $5^{\text {a }}$ ed. São Paulo: Martins Fontes, 1995. 